ORIGINAL ARTICLE

\title{
IMMUNOLOGIC AND CLINICAL OUTCOMES OF CHILDREN ON HAART: A RETROSPECTIVE COHORT ANALYSIS AT JIMMA UNIVERSITY SPECIALIZED HOSPITAL
}

\author{
Netsanet Workneh, MD, Tsinuel Girma, MD, Mirkuzie Woldie, MD, MPH
}

\begin{abstract}
BACKGROUND: The nature of human immunodeficiency virus infection in children has changed from an often fatal to a treatable chronic condition with highly active antiretroviral therapy. The outcome of the therapy depends on multiple factors such as non-adherence to treatment, selection of resistant viral strains, drug toxicity and socioeconomic factors. The objective of this study was to determine the immunologic and clinical outcomes of children who are on highly active antiretroviral therapy at the ART clinic, Jimma University Specialized Hospital. METHOD: A three -year's retrospective cohort analysis was conducted in July 2008 among children younger than 14 years of age getting highly active antiretroviral therapy in Jimma University Specialized Hospital. Data was collected using a pre-tested record review format and analyzed using SPSS for Windows version 16.0 and World Health Organization Anthro v2.0.2 software.

RESULT: Fifty three (55.2\%) of the 96 patients were female, the mean age at initiation of treatment was $6 \pm 4.2$ years and the mean follow-up period was $13.7 \pm 8$ months. By the time of the study, 69 (71.9\%) patients were still on follow-up, 7 (7.3\%) had died, 13 (13.5\%) were lost to follow-up and the remaining 7(7.3\%) were transferred-out. Majority (93.8\%) of them were at WHO stage $3 \& 4$ during initiation of treatment. Median Weight-for-age Z-score improved from 0.09 to 0.26 after 6 month of treatment. Immunologic treatment failure was seen in 11(11.5\%) of the patients; 5 of them also manifested clinical treatment failure. Severe drug toxicity occurred in 5 (5.2\%) cases. Presence of chronic gastroenteritis, WHO clinical stage 4 at initiation and appearance of new opportunistic infection after starting treatment were associated with immunologic treatment failure $(p<0.03)$.

CONCLUSION: Majority of the patients were having advanced clinical stage at initiation of treatment. Mortality rate and anthropometric changes of HIV infected children on highly active antiretroviral therapy were similar but immunologic treatment failure, loss to follow-up and severe drug toxicity were higher in this study compared to other reports from developing countries. Therefor, early diagnosis and treatment of HIV/AIDS and treatment monitoring should be strengthened.
\end{abstract}

KEY WORDS: HIVIAIDS, Children, HAART, immunologic and clinical outcome, Jimma.

\section{INTRODUCTION}

An estimated 2.3 million children worldwide were living with HIV type 1 by the end of 2006, more than 85 per cent of them being in Sub-Saharan Africa with estimated 1000 newly infected children daily (1-3). Without treatment, approximately half of them die before their second birthday; however, studies showed that lives can be saved and morbidity avoided with combination antiretroviral therapy (4). In Ethiopia by the end of July 2006, there were 45,595 patients ever started on ART in 132 facilities across the country among which only $4 \%$ were children (5). Promising developments have been seen in recent years in global efforts to address the AIDS epidemic although Pediatric care and treatment has lagged significantly behind those of adults (6).

\footnotetext{
${ }^{1}$ Department of Pediatrics and Child Health, P.O. Box 378, Jimma University

e-mail:nworkneh2004@yahoo.com,tsinuel@yahoo.com

${ }^{2}$ Department of Health Services Management, Jimma University, P.O. Box 1637, e-mail mirkuzie@yahoo.com
} 
Treatment outcome can be evaluated using virological, immunological or clinical criteria. The earliest indicator is virological (decrease or increase in viral load) followed by immunological treatment success or failure (rise or fall in CD4 count); usually clinical treatment failure becomes apparent much later. For this reason the outcome of HAART is best predicted by viral load determination (7). The goals for ART in children include restoring immune function, maintaining maximal suppression of viral replication, reducing HIV-related morbidity and mortality and improving quality of life and prolonging survival $(7,8)$.

In countries where it has been successfully introduced, ART has substantially changed the face of HIV infection. HIV-infected infants and children now survive to adolescence and adulthood (9). Despite potent treatment options, only $40-75 \%$ achieve satisfactory treatment outcomes in terms of viral suppression to undetectable levels one year after starting therapy (10). The explanation for this is multifactorial, including nonadherence to treatment, drug toxicity with subsequent treatment discontinuation, selection of resistant viral strains, suboptimal antiretroviral regimens, socioeconomic factors etc (7).

Though free ART being provided since 2005 in Jimma University Specialized Hospital (JUSH), the outcome was not studied. Moreover, although ART has changed the clinical course of HIV infection as mentioned above; severe drug toxicity, treatment failure, developmental delay and other unwanted outcomes are not uncommon (11-14). Therefore, the objective of this study was to assess immunologic and clinical outcomes of HIV infected children on HAART in JUSH.

\section{METHODS AND MATERIALS}

This retrospective cohort analysis was conducted from July 1-30, 2008 in JUSH, located $352 \mathrm{Km}$ Southwest of Addis Ababa. The hospital gives service for people living in Jimma Town and Southwest Ethiopia. The hospital gives VCT, PMTCT and free ART services according to Ethiopian National Guideline among others (8). Patients have regular follow-up for drug adverse effects, adherence and opportunistic infections. In addition, weight, height and head circumference are measured during each visit. CD4 determination was supposed to be done initially and every 6 months. Viral load determination was not possible during the study period.

All HIV-infected children age less than 14 year who were initiated on HAART at least 3 months before the study period were included in the study. In-patient and ART clinic charts were retrieved and reviewed using record review guide specifically developed for this study. Baseline clinical, laboratory and outcome data were collected.
Physicians working in the ART clinic collected the data after orientation about the study and data collection format. Data collection tool was pre-tested on 10 charts (included in the final analysis) with the objective of refining the record review guide. Data was cleaned, entered and analyzed using SPSS for Windows version 16.0 and WHO Anthro v2.0.2 software. Descriptive analysis including WAZ, HAZ and WHZ were calculated with $95 \%$ CI.

Permission for the study was obtained from Department of Pediatrics and Child Health and JUSH. Confidentiality was ensured and unauthorized persons didn't have access to the collected data. ART code number identified each subject. Treating physicians were informed about patients who were found to have treatment failure and patients were managed accordingly. The following operational definitions were used;

- WHO clinical criteria was used for diagnosis of Pneumocystis carinii pneumonia, Tuberculosis, Persistent diarrhea, chronic diarrhea and Oral candidiasis (15).

- Drug toxicity (Grade 3 \& 4) was considered after alternative explanations for the toxicity were excluded (8).

- Lost to follow-up: Refers to a patient who has missed three months of follow-up (16).

- Switch: Refers to a switch from first-line to secondline regimens (or second-line to third-line) (16).

- Treatment failure was diagnosed based on clinical and/or immunologic criteria suggested by WHO (8).

\section{RESULTS}

Of the 96 patients included in the study, $53(55.2 \%)$ were female. The mean age at initiation of HAART was $6 \pm$ 4.2 years and only $7(7.3 \%)$ children were younger than 18 months. Fifty two $(54.2 \%)$ patients were from Jimma City and $60(70.6 \%)$ had lost one or two of their parents. The primary caregivers were biological parents for 61 $(75.3 \%)$, grand parents for $13(16 \%)$ and guardian for 7 $(8.6 \%)$ of the children (Table 1$)$.

Concerning the initial HAART regimen, 73 (76.0\%) patients were started on AZT, 3TC, NVP and only 9 $(9.3 \%)$ were on stavudine based regimen. At initiation, $90(93.8 \%)$ cases were at WHO stage 3\&4, $74(77.1 \%)$ underweight (WFA $<5^{\text {th }}$ percentile), $61(63.5 \%)$ stunted (HFA $<5^{\text {th }}$ percentile) and $28(47.5 \%)$ had some degree of wasting (WFH $<90 \%$ ). Nine $(9.4 \%)$ patients were having severe acute malnutrition (two kwashiorkor and the remaining severe wasting). Tuberculosis was the commonest opportunistic infection diagnosed in 36 $(37.5 \%)$ patients before the initiation of HAART. The mean CD4\% for under 59 month children was $12.1 \pm 10.2$ and mean CD4 count for children 60 months or older was 191.7士 163) (Table 1). 
Table 1. Baseline characteristics of HIV infected children taking HAART at JUSH, 2008.

\begin{tabular}{|c|c|}
\hline Patient characteristics & Number (\%) \\
\hline \multicolumn{2}{|l|}{$\operatorname{Sex}(n=96)$} \\
\hline Male & $43(44.8)$ \\
\hline Female & $53(55.2)$ \\
\hline \multicolumn{2}{|l|}{ Age $(n=96)$} \\
\hline Children aged $<18 \mathrm{mo}$ & $7(7.3)$ \\
\hline Children aged 18-59 mo & $38(39.6)$ \\
\hline Children aged $\geq 60 \mathrm{mo}$ & $51(53.1)$ \\
\hline \multicolumn{2}{|l|}{ Parents $(n=84)$} \\
\hline Father alive & $30(35.3)$ \\
\hline Mother alive & $16(18.8)$ \\
\hline Both alive & $24(29.4)$ \\
\hline Neither alive & $14(16.5)$ \\
\hline \multicolumn{2}{|l|}{ caregivers $(\mathrm{n}=81)$} \\
\hline Mother or/and father & $61(75.4)$ \\
\hline Grand parent & $13(16)$ \\
\hline Guardian & $7(8.6)$ \\
\hline \multicolumn{2}{|l|}{ Anthropometry } \\
\hline \multicolumn{2}{|l|}{ Wt for age $(n=95)$} \\
\hline$<5^{\text {th }}$ centile & $74(77.1)$ \\
\hline$>5^{\text {th }}$ centile & $21(21.1)$ \\
\hline \multicolumn{2}{|l|}{ Ht for age $(n=88)$} \\
\hline$<5^{\text {th }}$ centile & $61(68.5)$ \\
\hline$>5^{\text {th }}$ centile & $27(31.5)$ \\
\hline \multicolumn{2}{|l|}{ Wt for $h t(n=88)$} \\
\hline$<70 \%$ & $5(5.7)$ \\
\hline $70-79 \%$ & $8(9.1)$ \\
\hline $80-89 \%$ & $15(17)$ \\
\hline$\geq 90 \%$ & $60(68.2)$ \\
\hline \multicolumn{2}{|c|}{$\begin{array}{l}\text { Severe acute malnutrition } \\
(\mathrm{WFH}<70 \text { and } / \text { or edema })(\mathrm{n}=96)\end{array}$} \\
\hline Yes & $9(9.4)$ \\
\hline No & $87(90.6)$ \\
\hline \multicolumn{2}{|l|}{ Tuberculosis $(n=96)$} \\
\hline Yes & $36(37.5)$ \\
\hline No & $60(62.5)$ \\
\hline \multicolumn{2}{|c|}{ diarrhea Persistent or chronic $(\mathrm{n}=96)$} \\
\hline Yes & $7(7.3)$ \\
\hline No & $89(92.7)$ \\
\hline \multicolumn{2}{|l|}{ Other OIs* $(n=96)$} \\
\hline Yes & $7(7.3)$ \\
\hline No & $89(92.7)$ \\
\hline \multicolumn{2}{|c|}{ Nevirapine prophylaxis at birth $(n=96)$} \\
\hline Yes & $3(3.1)$ \\
\hline No & $93(96.9)$ \\
\hline
\end{tabular}

*OI -opportunistic infections (Acute gastroenteritis, $\mathrm{PCP}$, candidiasis and bacterial pneumonia) 
Only $61(63.5 \%)$ cases had subsequent CD4 \% or count determination at least once during the follow-up. Mean CD $4 \%$ for children $<5$ years increased from $12.1 \pm 10.2$ to $22.5 \pm 8.5$ after 6 months of treatment. Mean CD4 count for children aged 5 years and above increased from $191.7 \pm 163$ to $417 \pm 223$ and $497 \pm 308$ after 6 and 12 months of treatment, respectively. Immunologic treatment failure was seen in $11(11.5 \%)$ patients; 6 (54.5\%) occurred between 6-12 months after initiation of treatment and $4(36.4 \%)$ after 12 months. Presence of chronic gastroenteritis, WHO clinical stage 4 during the initiation of HAART and appearance of new opportunistic infection after starting treatment were associated with immunologic treatment failure $(\mathrm{p}<0.05)$. Patients with chronic diarrhea at the time of initiation of HAART and those who developed new opportunistic infection after treatment was found to have 21 (95\% $\mathrm{CI}(2-231))$ and $12(95 \% \mathrm{CI}(2.1-68.7))$ times higher risk of developing immunologic treatment failure (Table 2).

Table 2. Factors associated with development of immunologic treatment failure in HIV infected children who were on HAART at JUSH, 2008

\begin{tabular}{|c|c|c|}
\hline variables & P-value* & Odds ratio $(95 \% \mathrm{CI})$ \\
\hline \multicolumn{3}{|l|}{ Age } \\
\hline$<5$ years & 0.5 & $1.2(0.3-4.4)$ \\
\hline$\geq 5$ years & & 1 \\
\hline \multicolumn{3}{|l|}{ Sex } \\
\hline Male & 0.4 & $1.47(0.4-5.4)$ \\
\hline Female & & 1 \\
\hline \multicolumn{3}{|l|}{ Parental status } \\
\hline Orphan & 0.4 & $2(0.2-18)$ \\
\hline At least one parent alive & & 1 \\
\hline \multicolumn{3}{|l|}{ Severe acute malnutrition } \\
\hline Present & 0.06 & $12.7(1-154.5)$ \\
\hline Absent & & 1 \\
\hline \multicolumn{3}{|l|}{ Tuberculosis } \\
\hline Present & 0.6 & $1.007(0.6-3.8)$ \\
\hline Absent & & 1 \\
\hline \multicolumn{3}{|l|}{ Chronic diarrhea } \\
\hline Present & 0.01 & $21.4(2-231)$ \\
\hline Absent & & 1 \\
\hline \multicolumn{3}{|l|}{ WHO stage } \\
\hline Stage 4 & 0.027 & $5.2(1.3-21.2)$ \\
\hline Stage 1-3 & & 1 \\
\hline \multicolumn{3}{|l|}{ Appearance of new $\mathrm{OI} \dagger$} \\
\hline Present & 0.008 & $11.8(2.1-65.7)$ \\
\hline Absent & & 1 \\
\hline
\end{tabular}

* Fisher's exact test used

†OI- opportunistic infections

Of the 96 children who had started HAART before March 31, 2008; 69 (71.9\%) were alive, 7 (7.3\%) had died, $13(13.5 \%)$ were lost to follow-up and $7(7.3 \%)$ were transferred to other treatment sites. Of the 7 deaths, 4 occurred within the first 3 months of treatment. The mean follow-up time was $13.7 \pm 8$ months. Median WFA Z-score showed improvement from base line 0.09 to 0.26 after 6 month of treatment. Similarly, median WHZ improved from base line 0.59 to 0.74 after 6 month of treatment. Opportunistic infection occurred in 7 (7.3\%) patients; tuberculosis being the commonest (4 out of 7 cases) and most of them occurred in the first 3 months. Clinical treatment failure was diagnosed in $6(6.2 \%)$ patients. Severe drug toxicity occurred in $5(5.2 \%)$ patients, mainly related to AZT. Eleven $(11.5 \%)$ patients switched to an alternative regimen, majority due to drug toxicity and interaction with anti-TB drugs (Figs 1, 2 and Table 3). 
Table 3. Clinical and immunologic outcomes of HIV infected children who were on HAART at JUSH, 2008.

\begin{tabular}{|c|c|}
\hline Event & Number (\%) \\
\hline $\begin{array}{l}\text { Outcomes }(\mathrm{n}=96) \\
\text { Alive } \\
\text { Died } \\
\text { Lost to follow up } \\
\text { Transferred }\end{array}$ & $\begin{aligned} 69 & (71.9) \\
7 & (7.3) \\
13 & (13.5) \\
7 & (7.3)\end{aligned}$ \\
\hline $\begin{array}{l}\text { Severe drug toxicity }(\mathrm{n}=79) \\
\text { Present } \\
\text { Absent }\end{array}$ & $\begin{array}{r}5(16.3) \\
74(93.7)\end{array}$ \\
\hline $\begin{array}{c}\text { Appearance of new OI }(\mathrm{n}=75) \\
\text { Present } \\
\text { Absent }\end{array}$ & $\begin{array}{c}7(9.3) \\
68(90.7)\end{array}$ \\
\hline $\begin{array}{l}\text { Immunologic treatment failure } \\
(\mathrm{n}=58) \\
\text { Present } \\
\text { Absent }\end{array}$ & $\begin{array}{l}11(19) \\
47(81)\end{array}$ \\
\hline $\begin{array}{c}\text { Clinical treatment failure }(\mathrm{n}=76) \\
\text { Present } \\
\text { Absent }\end{array}$ & $\begin{array}{c}6(7.9) \\
70(92.1)\end{array}$ \\
\hline $\begin{array}{l}\text { Change from initial regimen } \\
(\mathrm{n}=77) \\
\qquad \begin{array}{l}\text { Present } \\
\text { Absent }\end{array}\end{array}$ & $\begin{array}{l}11(14.3) \\
66(85.7)\end{array}$ \\
\hline
\end{tabular}

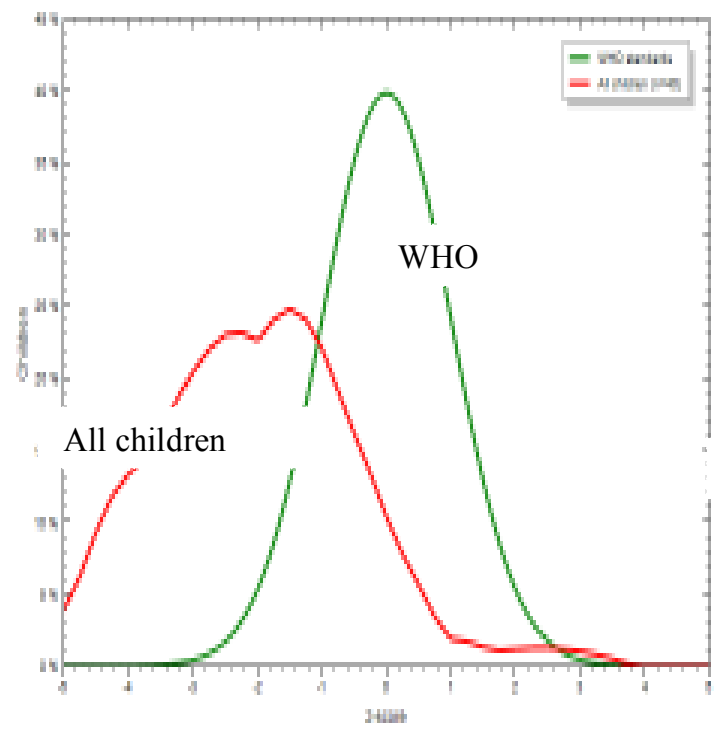

Baseline

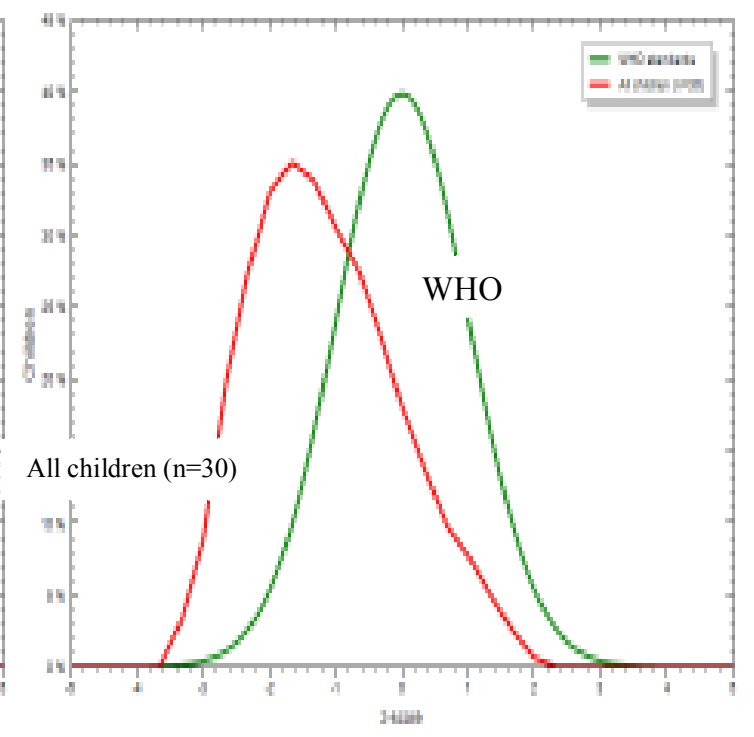

After 6 months

Figure 1. Change in WAZ (Weight for age Z score) after 6 months of treatment of HIV infected children who were on HAART at JUSH, 2008. 


\section{DISCUSSION}

The result of this study is comparable with similar pediatric cohorts in Africa and other developing countries in terms of mortality rate and anthropometric changes; but higher rate of defaulters, treatment failure, severe drug toxicity and regimen change were seen (17-26).

In this study, CD4 count or percent was not determined for nearly half of the patients during follow- up. Akileswaran and others suggested that the frequency of $\mathrm{CD} 4$ cell count monitoring of patients to be every 6 months (25). Other study proposed CD4 cell counts determination to be as often as monthly to every 3 months (27). The hospital had only one machine for CD4 determination which breaks frequently; otherwise according to the Ethiopian guideline it could have been done every 6 months.

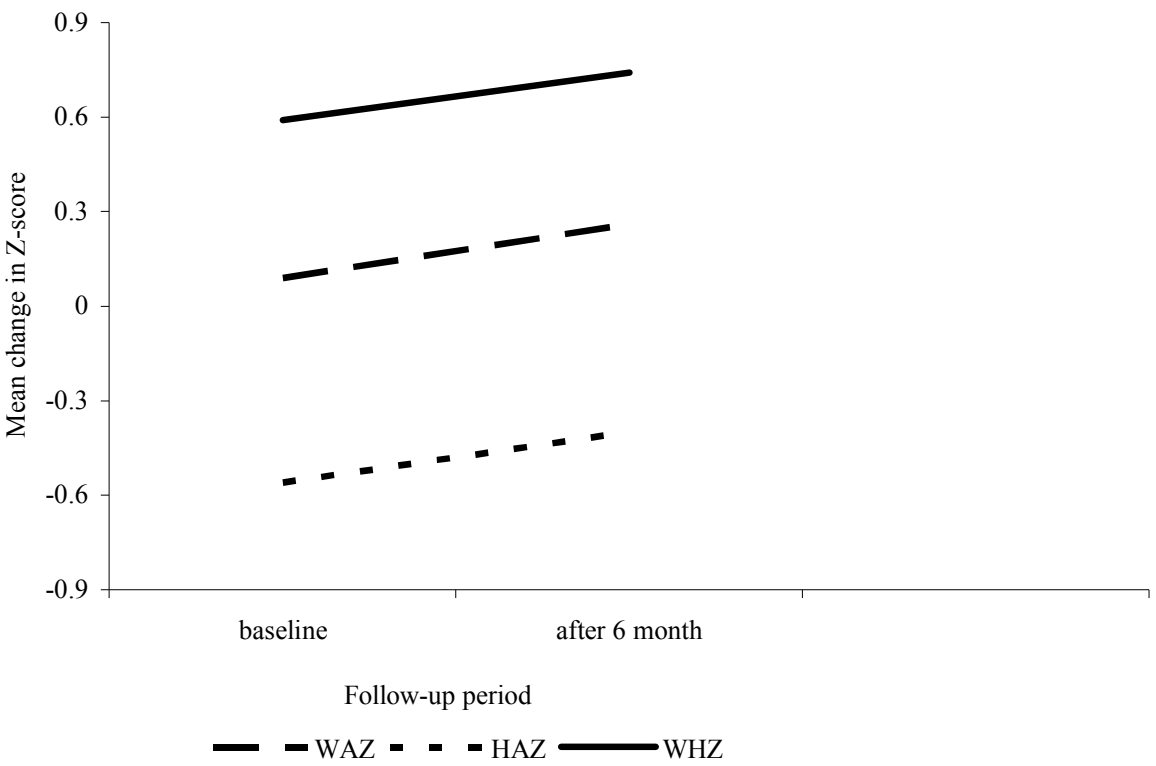

Figure 2. Change in mean $\mathrm{Z}$ score of nutritional indices of HIV infected children who were on HAART at JUSH, 2008.

Mortality rate of the current study was similar with other pediatric cohorts from low and middle income countries which reported in the range of $7 \%-20 \%(20,24)$. As in an adult Ethiopian HAART cohort, most of the deaths occurred within the first three months of therapy, indicating delay in diagnosis and initiation of treatment (29). Three out of 7 deaths were related to tuberculosis which may be complicated with immune reconstitution syndrome or drug toxicity as reported elsewhere $(17,18)$.

Among those diagnosed to have immunologic treatment failure, two patients had severe drug toxicity too. Only one of them reported poor adherence; another patient was given nevirapine prophylaxis during birth which can be possible cause for development of immunologic failure related to development of mutations and resistance to the drug (7). Advanced clinical stage during the initiation of treatment and appearance of new opportunistic infection after starting treatment were also associated with immunologic treatment failure. Presence of chronic gastroenteritis was associated with immunologic treatment failure as enteritis may interfere with the absorption of the drugs.

In this study, clinical treatment failure was seen in five of the children diagnosed to have immunologic treatment failure which could be due to occurrence of drug-resistant strains $(21,30)$. As the report from South Africa revealed more than $80 \%$ antiretroviral drugresistant virus among patients who experienced treatment failure after first HAART regimen (23).

The rate of lost to follow up in this study was inline with the finding among African adults, which reported a weighted mean of $79 \%$ retention at 12 month (24). But, it was different form the South African pediatric cohorts where no children were lost to follow-up despite many of the cohort had to travel long distances. Reasons mentioned for $100 \%$ retention of patients included immediate improvement which may have convinced caregivers of the effectiveness of HAART and the 
ongoing care; and treating caregivers and children at the same site may have created stronger ties to families resulting in better retention $(19,31)$. As this study didn't look for the reasons, detailed study is needed to know the cause of loss to follow-up.

Higher rate of regimen change due to severe drug toxicity (mainly Zidovudine related) was seen in our study in contrast to the côte divôire and South African results (24), but significantly lower than the percentage recorded for African adult cohorts which showed a range of $14.3 \%-80.2 \%(25)$. Weight gain shown in our study is also similar to other studies $(24,25)$.

In conclusion, most patients were in WHO stage 3 and 4 at initiation of HAART and most deaths were within 3 months of therapy. Significant number of patients didn't have follow-up CD4 determination. Satisfactory improvement in patients' weight and height was seen after initiation of HAART. The immunologic treatment failure, drug toxicity, regimen change and defaulter rate were higher in our study when compared with others. Presence of chronic gastroenteritis, WHO clinical stage 4 during the initiation of HAART and appearance of new OI after starting treatment were associated with immunologic treatment failure.

Therefore; PMTCT should be strengthened, since it is the best way of targeting pediatric HIV/AIDS. Early diagnosis and treatment and CD4 monitoring should be strengthened; as there is no viral load determination which is more important parameter of assessing treatment response.

Patients who present with chronic Gastroenteritis, WHO clinical stage 4 disease and those who manifest new OI need to be managed carefully as they are at greater risk of developing treatment failure. The cause of high rate of loss to follow up should be further investigated and managed. We also recommend detailed and well designed studies with larger number of patients.

\section{ACKNOWLEDGEMENTS}

We acknowledge Jimma University for financing the study. We also extend our thanks to all individuals who participated in the study in one way or another.

\section{REFERENCES}

1. USAID. Project Profiles: Children Affected by HIV/AIDS. USAID, 2005.

2. UNAIDS/WHO. AIDS epidemic update. UNAIDS/WHO, 2006.

3. WHO. Taking Stock: HIV in Children. Geneva: WHO, 2006.

4. Bolton-Moore C, Mubiana-Mbewe M, Cantrell RA, et al. Clinical Outcomes and CD4 Cell Response in Children Receiving Antiretroviral
Therapy at Primary Health Care Facilities in Zambia. JAMA, 2007; 298:1888-99.

5. Federal Ministry of Health. National HIV/AIDS Prevention and Control Office. AIDS in Ethiopia Sixth Report. Addis Ababa, FMoH, 2006.

6. UNICEF. A Call to Action: Children, the missing face of AIDS, New York: UNICEF, 2005.

7. Niehues T, Lyall H. Antiretroviral Therapy in Children. In: Hoffmann C, Rockstroh JK \& Kamps BS. (eds). HIV Medicine, Paris, flying publisher, 2006:375-80.

8. Federal Ministry of Health. Federal HIV/AIDS Prevention and Control Office: Guidelines for Paediatric HIV/AIDS Care and Treatment in Ethiopia. FMoH, 2007.

9. WHO. Antiretroviral therapy for HIV infection in infants and children: towards universal access: recommendations for a public health approach. WHO, 2006.

10. Jensen-Fangel $\mathrm{S}$. The effectiveness of highly active antiretroviral therapy in HIV-infected patients. Dan Med Bull, 2004; 51:371-92.

11. Puthanakit T, Aurpibul L, Oberdorfer P, et al. Hospitalization and Mortality among HIVInfected Children after Receiving Highly Active Antiretroviral Therapy. Clin Infect Dis, 2007 ; 44(4): 599-604.

12. Ferradini L, Laureillard D, Prak N, et al. Positive outcomes of HAART at 24 months in HIV-infected patients in Cambodia. AIDS, 2007; 21 (17):2293-301.

13. Ylitalo N, Brogly S, Michael D, et al. Risk Factors for Opportunistic Illnesses in Children with Human Immunodeficiency Virus in the Era of Highly Active Antiretroviral Therapy. Arch Pediatr Adolesc Med, 2006; 160:778-787.

14. Foster CJ, Biggs RL, Melvin D, et al. Neurodevelopmental outcomes in children with HIV infection under 3 years of age. Developmental Medicine \& Child Neurology, 2006; 48: 677-682.

http://journals.cambridge.org/action/ displayAbstract? aid=453319. Accessed April 15, 2008.

15. WHO. Pocket book of hospital care for children: guidelines for the management of common illnesses with limited resources. WHO, 2005.

16. WHO. Patient monitoring guidelines for HIV care and antiretroviral therapy (ART). WHO, 2006.

17. Verweel G, Annemarie MC, Rossum VA, et al. Treatment with Highly Active Antiretroviral Therapy in Human Immunodeficiency Virus Type 1-Infected Children Is Associated With a 
Sustained Effect on Growth. Pediatrics, 2002; 109(2):25.

18. Nachman SA, Lindsey JC, Moye J. Growth of human immunodeficiency virus-infected children receiving highly active antiretroviral therapy. Pediatr Infect Dis J, 2005; 24:352-7.

19. Janssens B, Raleigh B, Soeung S, et al. Effectiveness of Highly Active Antiretroviral Therapy in HIV-Positive Children: Evaluation at 12 Months in a Routine Program in Cambodia. Pediatrics, 2007; 120: 1134-1140.

20. Reddi A, Leeper SC, Grobler AC, et al. Preliminary outcomes of a paediatric highly active antiretroviral therapy cohort from KwaZulu-Natal, South Africa. BMC Pediatrics. 2007; 7:13.

21. Nesheim SR, Kapogiannis BG, Soe MM, et al. Trends in Opportunistic Infections in the Preand Post-Highly Active Antiretroviral Therapy Eras Among HIV-Infected Children in the Perinatal AIDS Collaborative Transmission Study, 1986-2004. Pediatrics, 2007; 120 (1):100-9.

22. Rouet F, Fassinou P, Inwoley A. Long-term survival and immuno-virological response of African HIV-1-infected children to highly active antiretroviral therapy regimens. AIDS, 2006; 20(18):2315-9.

23. Marconi VC, Sunpath H, Lu Z, et al. Prevalence of HIV-1 drug resistance after failure of a first highly active antiretroviral therapy regimen in KwaZulu Natal, South Africa. Clin Infect Dis, 2008; 46 (10):1589-97.

24. Fassinou P, Elenga N, Rouet F, et al. Highly active antiretroviral therapies among HIV-1infected children in Abidjan, Cote d'Ivoire. AIDS, 2004; 18:1905-1913.

25. Akileswaran C, Lurie MN, Flanigan TP, Mayer KH. Lessons Learned from Use of Highly Active Antiretroviral Therapy in Africa. Clinical Infectious Diseases, 2005; 41:376-85.

26. WHO. Scaling up Antiretroviral Therapy in Resource-limited Settings: Treatment Guidelines for a Public Health Approach: 2003 Revision. Geneva: WHO, 2004.

27. Bagchi S, Kempf MC, Westfall AO, et al. Can Routine Clinical Markers Be Used Longitudinally to Monitor Antiretroviral Therapy Success in ResourceLimited Settings? Clinical Infectious Diseases, 2007; 44:135-8.

28. Mahajan AP, HoganB JH, Snyder B, et al. Changes in total lymphocyte count as a surrogate for changes in CD4 count following initiation of HAART: Implications for monitoring in resource-limited settings. $J$ Acquir Immune Defic Syndr, 2004; 36 (1):567-75.

29. Jerene1 D, Næss A, Lindtjørn B. Antiretroviral therapy at a district hospital in Ethiopia prevents death and tuberculosis in a cohort of HIV patients. AIDS Research and Therapy, 2006; 3:10. http://www.aidsrestherapy.com/content/3/1/10 Accessed April 15, 2008.

30. Hamers RL, Schuurman R, Vugt MV, et al. AIDS treatment in Africa: the risk of antiretroviral resistance. Ned Tijdschr Geneeskd, 2007;151 (48):2666-71.

31. Deribe K, Hailekiros F, Biadgilign S, Amberbir A, Kebede B. Defaulters from antiretroviral treatment in Jimma University Specialized Hospital, Southwest Ethiopia. Tropical Medicine and International Health, 2008; 13 (3): 328-333. 